Article

\title{
Visualization of Operational Performance of Grid-Connected PV Systems in Selected European Countries
}

\author{
Bala Bhavya Kausika *, Panagiotis Moraitis $\mathbb{D}^{D}$ and Wilfried G. J. H. M. van Sark \\ Copernicus Institute, Utrecht University, Heidelberglaan 2, 3584 CS Utrecht, The Netherlands; \\ P.Moraitis@uu.nl (P.M.); w.g.j.h.m.vansark@uu.nl (W.G.J.H.M.v.S.) \\ * Correspondence: b.b.kausika@uu.nl
}

Received: 20 April 2018; Accepted: 21 May 2018; Published: 23 May 2018

\begin{abstract}
This paper presents the results of the analyses of operational performance of small-sized residential PV systems, connected to the grid, in The Netherlands and some other European countries over three consecutive years. Web scraping techniques were employed to collect detailed yield data at high time resolution $(5-15 \mathrm{~min})$ from a large number $(31,844)$ of systems with $741 \mathrm{MWp}$ of total capacity, delivering data continuously for at least one year. Annual system yield data was compared from small and medium-sized installations. Cartography and spatial analysis techniques in a geographic information system (GIS) were used to visualize yield and performance ratio, which greatly facilitates the assessment of performance for geographically scattered systems. Variations in yield and performance ratios over the years were observed with higher values in 2015 due to higher irradiation values. The potential of specific yield and performance maps lies in the updating of monitoring databases, quality control of data, and availability of irradiation data. The automatic generation of performance maps could be a trend in future mapping.
\end{abstract}

Keywords: performance ratio; annual yield; GIS; PV system; spatial analyses

\section{Introduction}

Recent years have seen a constant growth in solar photovoltaic technology (PV). Several countries have utilized this potential to create a competitive market in view of a green energy future, which led to an increase in small and medium-sized residential solar PV installations [1,2]. These small-sized installations (with capacities less than $10 \mathrm{kWp}$ ) are scattered and operate under diverse conditions without adequate monitoring equipment. Studies show that most of these systems perform adequately, but due to a lack of systematic data collection, performance validation was mainly focused on specific geographic areas with a limited amount of systems [3,4].

A "Photovoltaic Geographical Information System" (PVGIS) system was designed to provide performance assessments to an accuracy that is suitable for small installations and for estimating the potential solar energy over large regions at any location in Europe [5]. Although this large-scale GIS (Geographic Information System) database of solar radiation and ambient temperature has been created to estimate energy output from crystalline silicon PV systems and solar water heating systems, it does not provide continuous monitoring or performance evaluation for small-sized, grid-connected PV systems.

Currently available monitoring technology in the market is capable of providing owners with sophisticated web tools to monitor their production and system performance at any point during the day, besides measuring energy production. With the advent of such hardware and smart-metering 
technology, high-resolution monitoring data is publicly available, which is uploaded daily on web platforms, however, in some cases only owners can view this data.

With the huge amount of data that is available due to the monitoring equipment, abnormalities can be compared with additional data (remote sensing imagery) for identification of reasons for underperformance or fault detections [6]. Monitoring small grid-connected PV systems to minimize financial losses has also been explored [7] along with the need for long-term monitoring for reliability and increased PV performance [4]. In [1,8], the authors show the importance of using a graphical supported analysis of monitoring and operation of PV installations for fault detections. In our earlier work $[9,10]$, we show how technical aspects and geographical location of PV systems affect PV performance. In this paper, geographic information systems (GIS) are employed to analyze, visualize, and map PV monitoring data from five countries, namely, The Netherlands, France, Germany, Belgium, and Italy. We also present and discuss methods for visualization and detection of underperforming or overperforming systems for further analysis, performance ratio analysis of systems, and spatio-temporal mapping of performance differences.

\section{Method}

Data used for the analyses was collected using online services provided by Solar Log [11] and SMA [12], which also ensured data legitimacy. Solar Log has users over a hundred countries and is one of the major key players in monitoring applications, though it has lost a lot of its clients after 2015. SMA is one of the specialists in photovoltaic inverter system technology. The code used in this research was developed to extract online data and was designed using Python programming [13]. The objective of the web scraping code was to mimic human navigation through web pages of SMA and Solar Log, and to locate and save information that was available to the user [9]. This means that the monitoring information pages of different PV systems was retrieved and saved accordingly. This information was later organized into datasheets. In this way, high temporal resolution yield data (5 min) and other system metadata like orientation, tilt, type of module, etc. were obtained. Recently, privacy constraints have been put on the data, and these data are not available publicly anymore. In total, data from about 31,844 systems were collected for the years 2012-2016 from 5 different countries in Europe, namely, The Netherlands, France, Germany, Belgium, and Italy.

In order to calculate the performance ratio (PR) of all the systems, system yield and reference yield are required. System yield is obtained from the data collected by web scraping and reference yield is calculated using the Olmo model [14]. This model requires irradiation data [15]. Hourly global horizontal irradiation data obtained from the 31 ground-based stations of the Royal Netherlands Meteorological Institute (KNMI) were used to compute the reference yield for The Netherlands. These stations cover the entire country. For each installation in the database, irradiation data was collected by linking it to the closest ground station, in order to minimize the uncertainties in the irradiation data. Note that no system was further away than $\sim 30 \mathrm{~km}$ from the nearest KNMI station. The tilt and orientation for every system has also been obtained from web-scraped data of PV systems. The Olmo model was then used to calculate the total irradiation in the plane of array on an hourly basis. This study does not take into account effects such as shading as the aim of the paper is to visualize performance rather than detect reasons behind over- or underperformance [16]. The PR was calculated using Equation (1), where $Y_{f}$ is the final system yield and $Y_{r}$ is the reference yield [15]. Since high-resolution, up-to-date annual irradiation data was not available for the rest of the countries, PR was calculated only for The Netherlands.

$$
P R=\frac{Y_{f}}{Y_{r}}
$$

Geographic Information System (GIS) is a "powerful set of tools for collecting, storing, retrieving at will, transforming, and displaying spatial data from the real world" [17]. Based on the principles of geography, cartography, etc., GIS is used for integration of different data types. It is a very powerful tool when it comes to analyses of spatial information, layering or organizing layers of information into 
visualizations using maps and 3D scenes [18]. There are several GIS software packages available in the market today, but ArcGIS [19] is a leading licensed tool for performing powerful geo-analyses, which will be used in this paper as an example tool.

Visualizations of the performance ratio, the locations of the installations, and yield and performance maps were created using the ArcGIS platform. An inverse distance weighted (IDW) interpolation technique was used to create the performance ratio maps and specific yield maps for different years of data collection. Although data from around 31,800 systems was available (2012-2016), only those systems that recorded data continuously for three consecutive years (between 2014 and 2016) were used to compare the differences in yield generation. This provides an understanding of how system performance varies spatially (over geographic areas) and helps in identifying outliers in the data. In addition to being able to visualize the results, looking into the diffusion of distributed systems within a country or area allows for the computation of geo-statistics pertaining to the region which are useful for policy implementation.

\section{Results and Discussion}

From 2011 to 2016, data from more than 31,800 systems was collected and analyzed. However, only 7894 of them were consistently delivering valid data for more than 350 days per year for at least three consecutive years (2014-2016). The total capacity of these systems was about $102 \mathrm{MWp}$ with $56 \%$ of them having a lower capacity than $10 \mathrm{kWp}$ and only $1.1 \%$ being larger than $50 \mathrm{kWp}$ (see Figure 1). The mean value was $12 \mathrm{kWp}$. The spatial distribution of all the installations with system size information is illustrated in Figure 2. The variation in average size and composition of the systems in each country is a direct reflection of the country's policies on PV subsidy schemes.

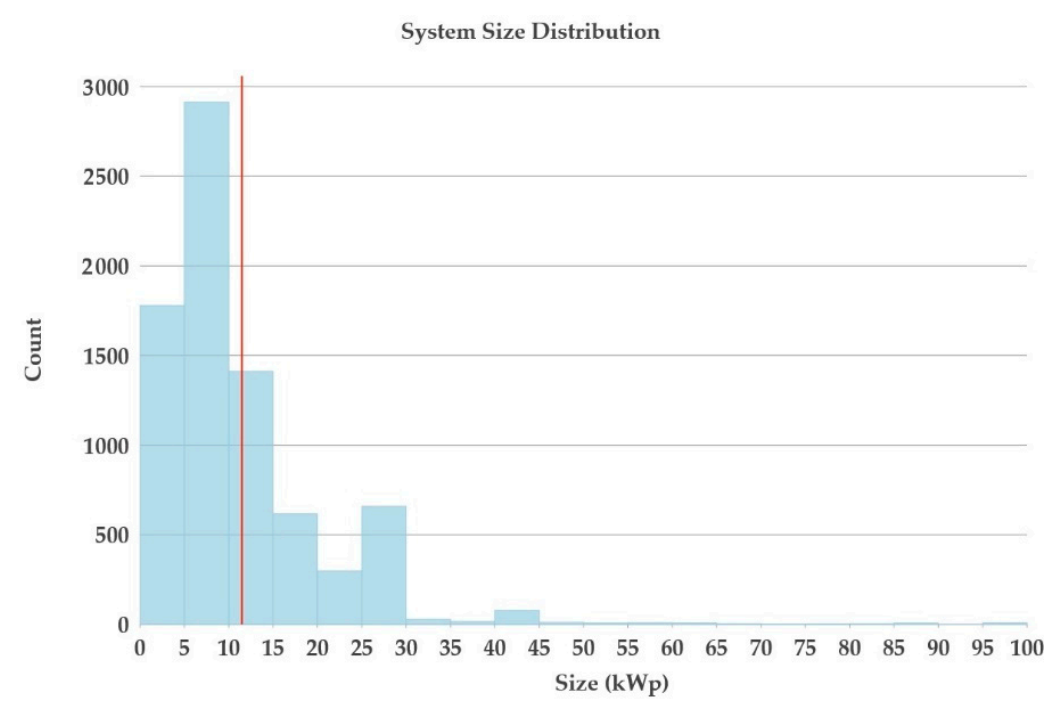

Figure 1. System size distribution of systems with capacity of less than $100 \mathrm{kWp}$ for five countries. The red line illustrates the mean value of $12 \mathrm{kWp}$.

A high concentration of small-scale domestic installations is observed in Germany, Belgium, and The Netherlands with $64 \%$ of the systems in Germany. The Netherlands and Belgium have most of the systems' total capacity under $5 \mathrm{kWp}$. While in Germany only $7.2 \%$ of the installations fall in this category, $45 \%$ of the PV of the systems installed are still below $10 \mathrm{kWp}$. Though the monitoring procedure might have started at a later time, most of the systems from the sample were installed between 2008 and 2014.

Figure 2 shows the location of each PV system, categorized by system capacity. Data collected from the monitoring systems and organized in a database was imported into GIS to create this map. Clearly, large numbers of systems are concentrated in Germany, Belgium, and The Netherlands. Some of the 
systems had faulty location information and hence were not included in the map. Most of the systems are also concentrated in the North where irradiation is lower, rather than in the South where there is higher irradiation.

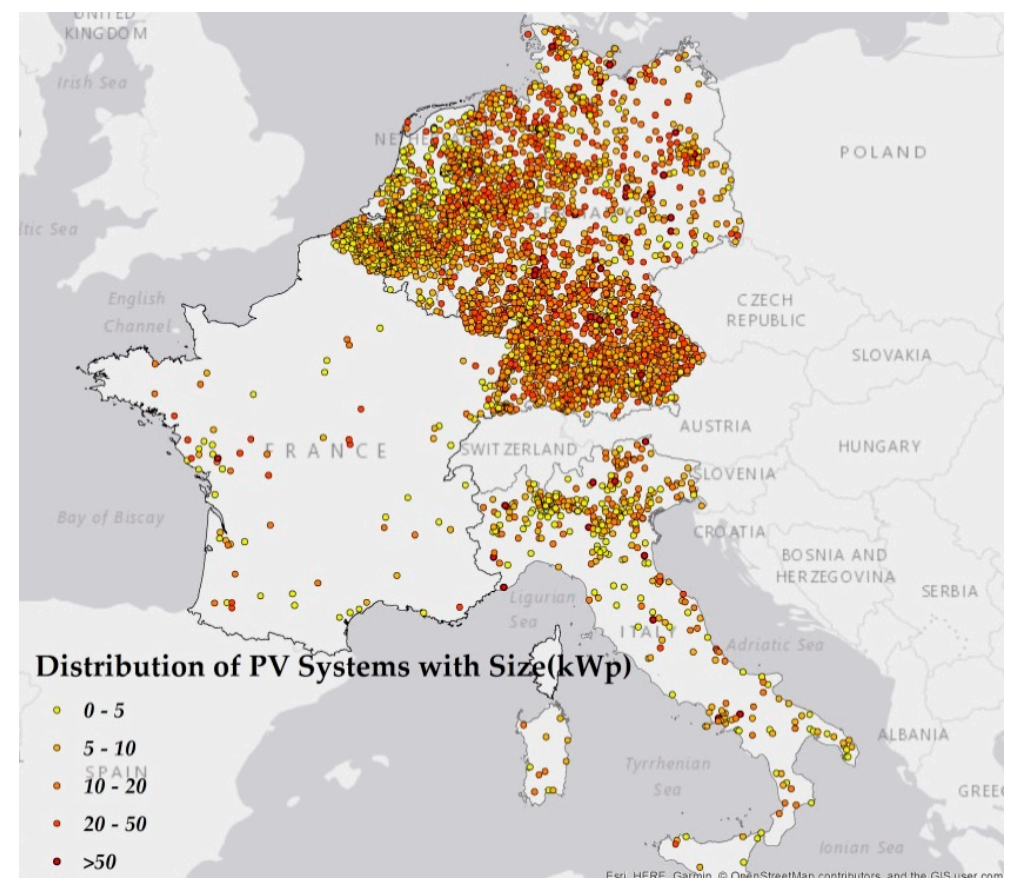

Figure 2. Spatial distribution of the data sample for The Netherlands, Belgium, France, Germany, and Italy.

\subsection{Yield Analysis and Performance Ratio}

The available data was found to be varying through different time periods as new installations were added every year. Also, not all the systems recorded data for all the years. Therefore, only those systems that had been consistently delivering data for the three consecutive years (2014-2016) have been considered for analysis. Furthermore, since the interest is in monitoring small-scale installations, annual yield analysis of systems below $20 \mathrm{kWp}$ for the years 2014-2016 has been conducted for The Netherlands, France, Germany, Belgium, and Italy. These countries were found to have the highest amount of data records from the data collection.

The mean value and the standard deviation of the performance of systems of each sample is shown in Figure 3: here we show the annual specific yield, i.e., generated amount of energy divided by system capacity ( $\mathrm{kWh} / \mathrm{kWp}$ ). These are known to be affected by a number of environmental and operational factors [20]. Moreover, a wider spread of yearly yield values can be expected from countries covering larger areas as a result of the variation of irradiation levels at different latitudes. The distribution of annual system yield for The Netherlands, Belgium, Germany, and Italy is shown in Figure 4. France has only 95 installations between 2014 and 2016 out of which 76 systems are below $20 \mathrm{kWp}$ capacity, while Germany has nearly 3900 systems, and Belgium 1700. Therefore, France has higher mean yields and only four outliers due to sample size. Between 2014 and 2016, the annual yield increased in 2015. However, the decrease or increase in yields falls within standard deviations, but at the same time relates directly to the decrease or increase in solar irradiation on a country level.

Performance ratio (PR) analysis was conducted for The Netherlands which revealed a mean PR value of $79 \%$ for the year 2016 and $80 \%$ for 2014 and 2015 . The PR values were calculated with an average daily PR value over a year. These values are close to the results of an earlier study performed in Germany [21]. The sample size for this estimation was about 600 installations. The number of PV installations in The Netherlands significantly increased from 2009, but their performance dropped 
in 2016 in comparison to 2014 (Figure 5). Systems installed in 2013 performed well in 2014 and 2015, while in 2016, a lot of outliers were observed. In some cases, the large variation in PR values could also be due to technical errors in data collection.

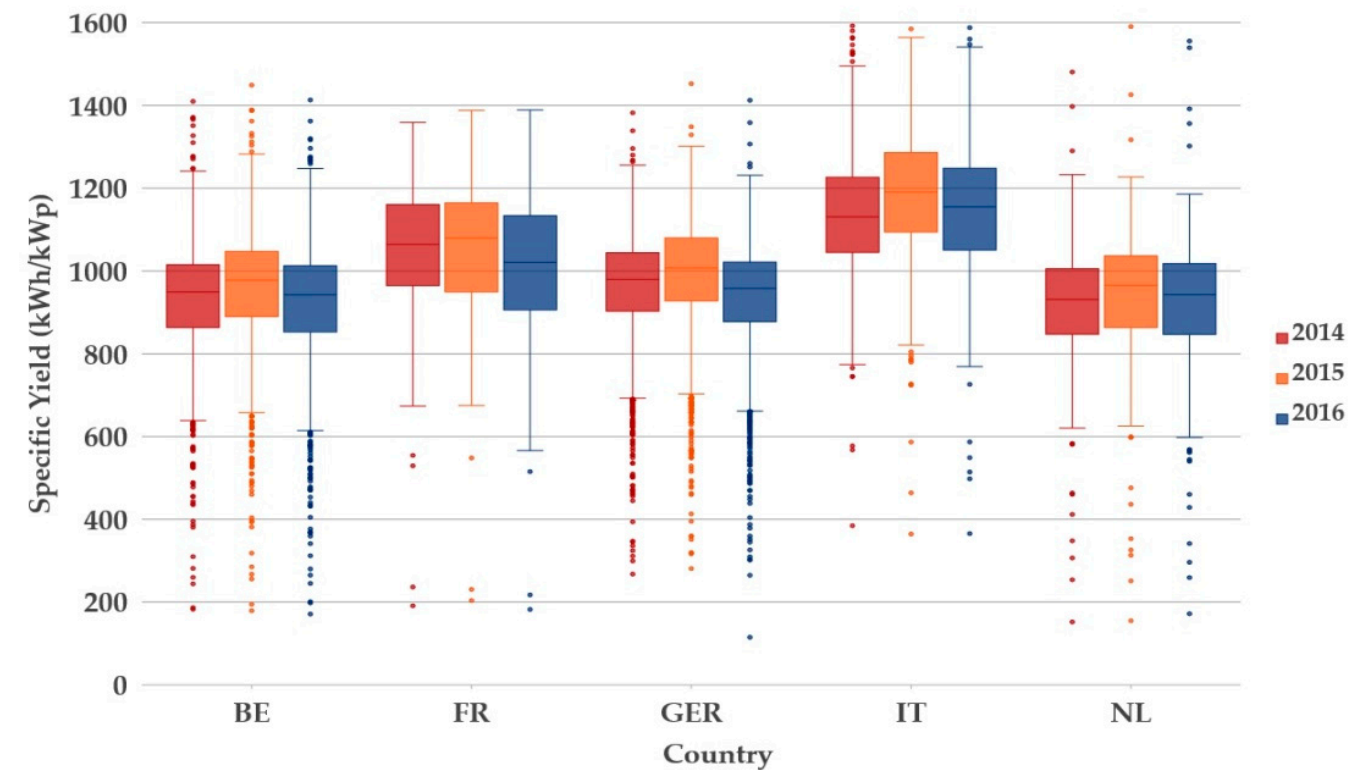

Figure 3. Distribution of specific yield by country from 2014 to 2016 for systems less than $20 \mathrm{kWp}$. Highest yields were recorded in 2015, with Italy (IT) having the highest mean, followed by France (FR), Germany (GER), Belgium (BE), and The Netherlands (NL), respectively.
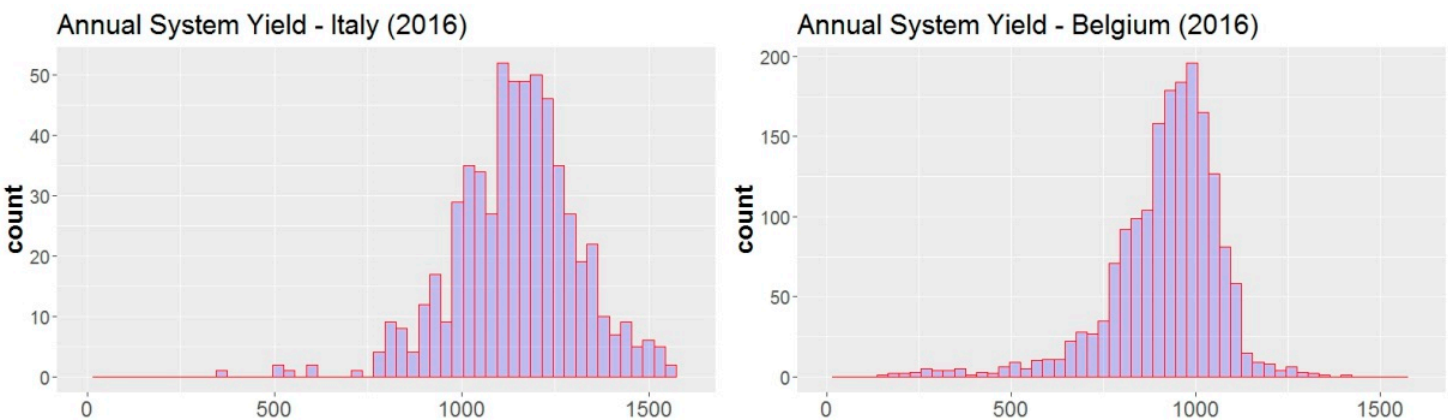

Annual System Yield - Germany (2016)
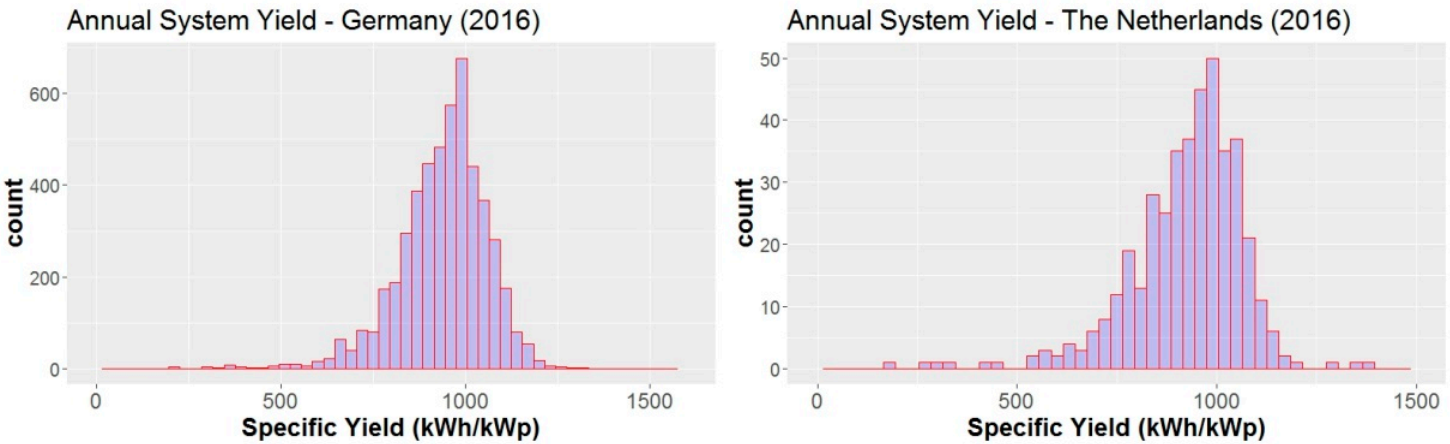

Figure 4. Distribution of specific yield for the year 2016 for Italy, Germany, Belgium, and The Netherlands. 
PR Distribution for Installations from 2009-2013

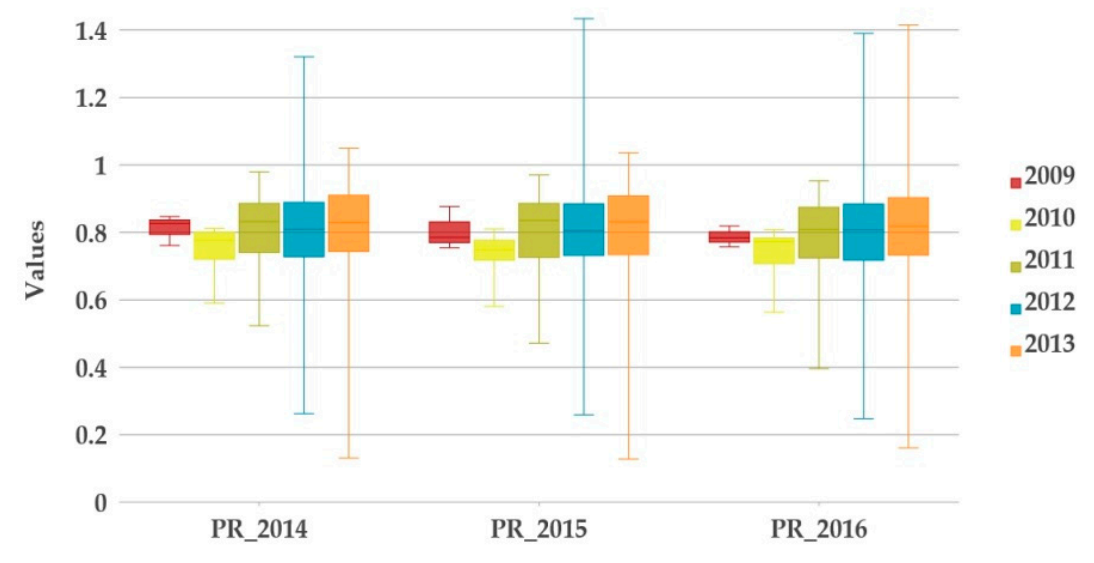

Figure 5. Distribution of performance ratio of The Netherlands between 2014 and 2016 for systems that have been installed from 2009 to 2013.

\subsection{Geographical Variation of Specific Yield}

Point data (vector information) collected from the web monitoring services has been converted to images (raster information) by using interpolation techniques. Interpolated data is visualized using color scales stretched using specific bins of annual yield values. From these images/maps, outliers can be quickly discerned to locate PV systems with minimum or maximum yields, thus providing a starting point for further analyses into the reason behind the system's under- or overperformance. The maps can be compared to the country irradiance maps to check for irradiation trends in the particular year, as yield values are related to irradiation values. This provides a quick approximation of the variation of performance over the country.

Figure 6 shows an interpolated map of annual yield of The Netherlands and Italy for three years with dots representing the location of the systems. Inverse Distance Weighted (IDW) interpolation technique was used to generate the maps. Higher yield values have warmer and darker shades (reds) and lower yield values have a blue shade. A variation in yield values is observed within the countries, while it should be noted that these variations can further be optimized using different color scales and data stretching methods. A few examples of this are shown below.

Although variations over the years are not very prominent because of the type of stretch used for data visualization and the data sample (system size up to $20 \mathrm{kWp}$ ), it could still be distinguished that 2015 has higher annual yields. A min-max stretch was used to visualize data with the same scale of minimum and maximum values for the three years to maintain consistency.

When using a different data stretching method (see, for example, Figure 7a), extreme deviations in data (bright spots) can be identified around systems with extreme yield values. These extreme values carry a higher weight factor during interpolation causing the spot or bleeding effect. As mentioned earlier, these spots can be separated out as outliers or as inadequately performing systems. Moreover, if high resolution irradiation data is available, the database of collected information could be explored by irradiation zones in addition to spatial diffusion or technical criteria.

An example of different stretching techniques is shown in Figure 7, in which two types of data stretching were used over a color scale. In Figure 7a, a percentage clip method was used, where the values displayed are cut-off percentages of highest and lowest values, while Figure $7 \mathrm{~b}$ displays values between the actual or set minimum and maximum. A smoothing effect can also be seen in Figure $7 \mathrm{~b}$, while it is easier to pick out underperforming or overperforming systems to analyze them further from Figure 7a. 

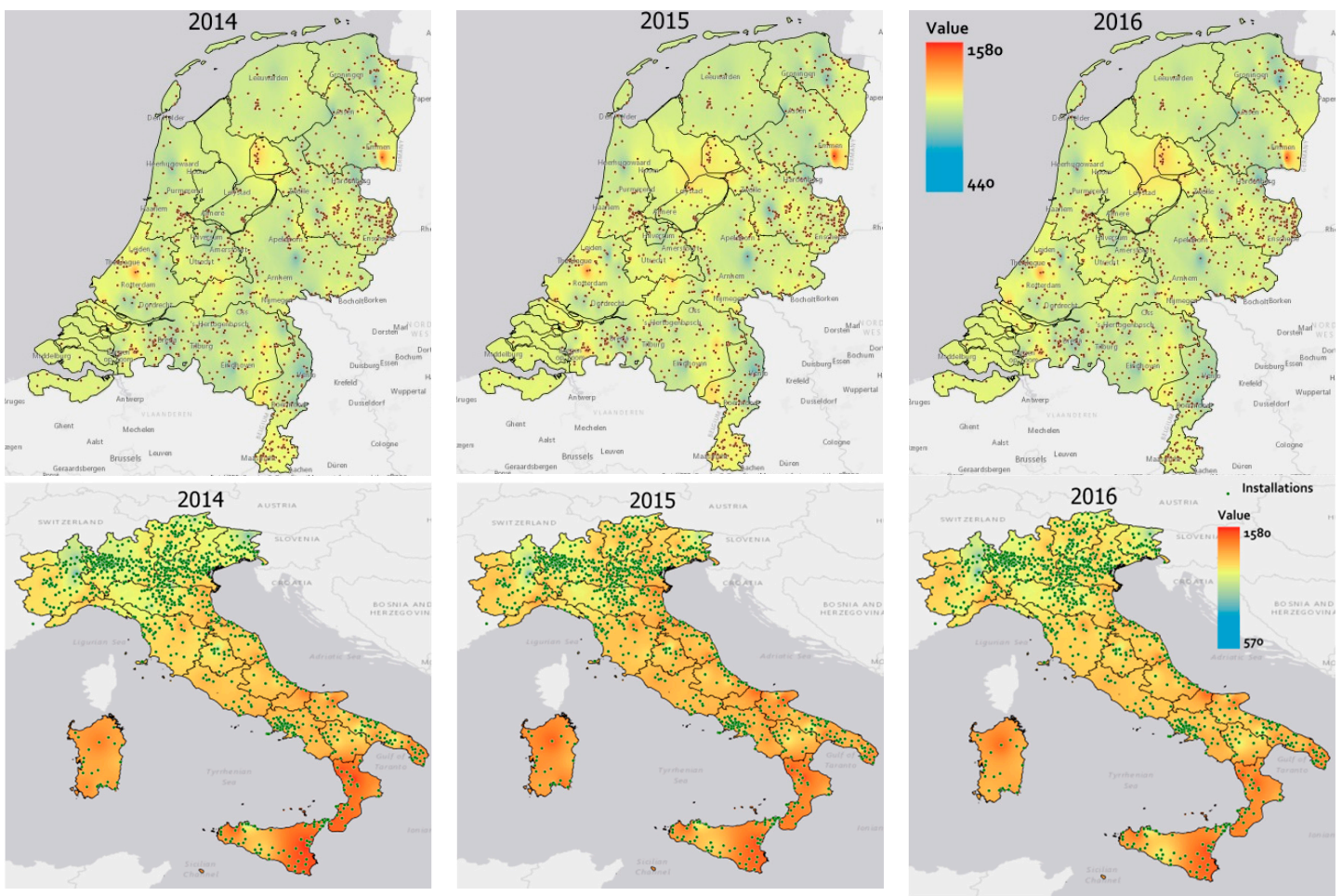

Figure 6. Annual specific yield variation from the installations (up to $20 \mathrm{kWp}$ ) in The Netherlands (above) and Italy (below) for the years 2014-2016, visualized using interpolation techniques.
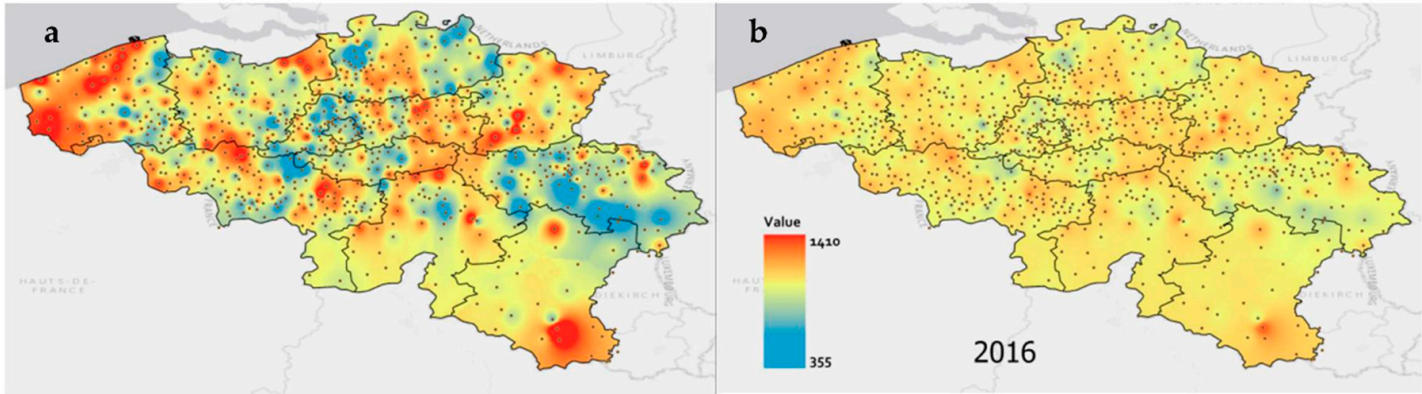

Figure 7. Annual specific yield variation from the installations (up to $20 \mathrm{kWp}$ ) for Belgium visualized using two different types of data stretching for 2016. Data stretching techniques (a) percent clip and (b) min-max used for data visualization.

Another example of the power of GIS in visualization is shown in Figure 8, where the mean specific yield for Germany using different thresholds of system sizes is presented. The variation in specific yield of systems up to $20 \mathrm{kWp}$ is much smoother compared to when only systems up to $10 \mathrm{kWp}$ are considered. For example, the systems in the highlighted area (red box in both images) shows underproduction when compared with larger systems $(<20 \mathrm{kWp})$ while, on comparison with smaller systems $(<10 \mathrm{kWp})$, they seem to be performing adequately. Also, it can be seen that a few systems seem to be less efficient in both categories, which means they could actually suffer from a malfunction. 


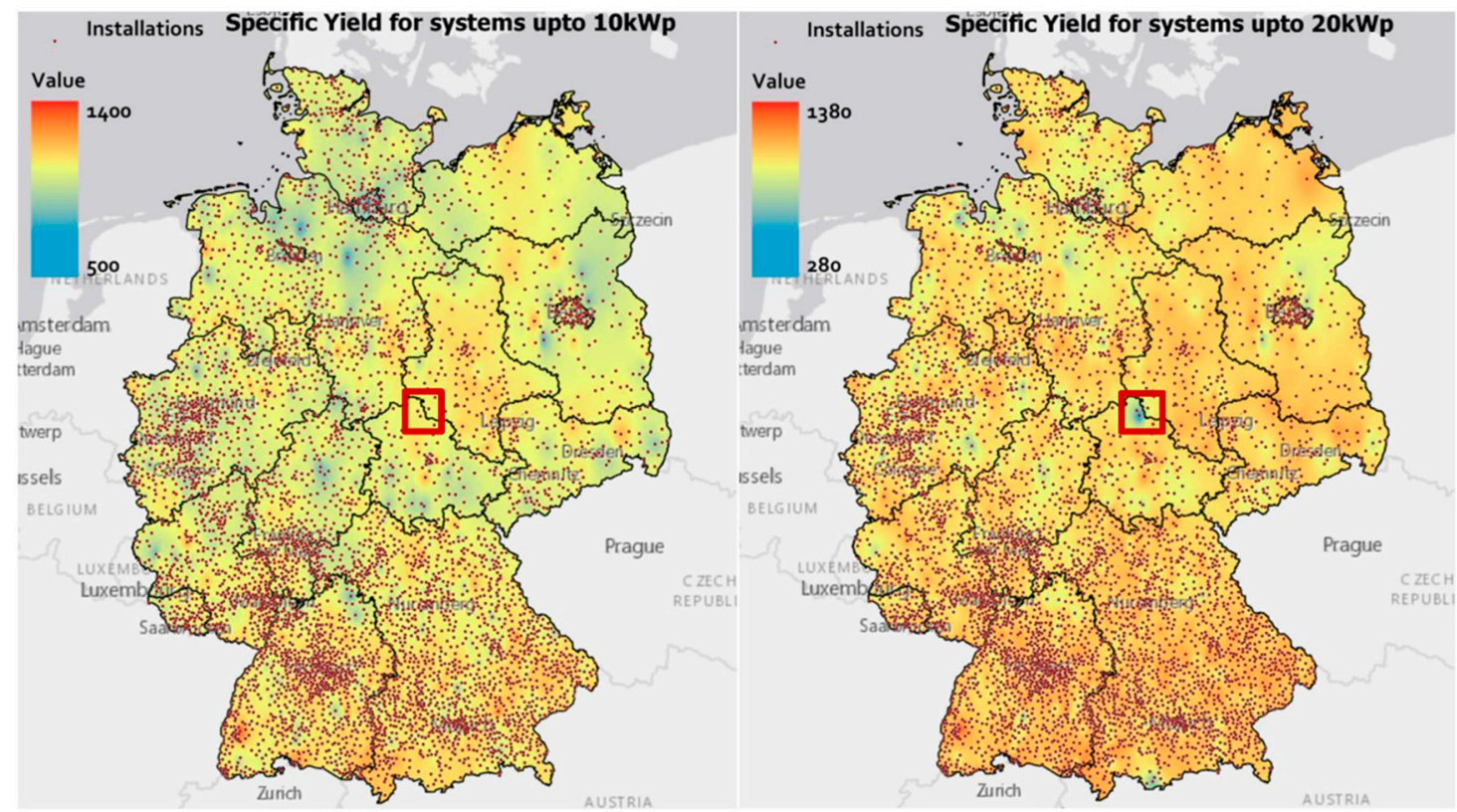

Figure 8. Specific yield variation from the installations in the Germany, for different system sizes.

\subsection{Mapping Performance Differences}

Differences in specific yield for three years for The Netherlands are shown in Figure 9. This has been calculated based on the yield maps generated by interpolation. Areas in red show decrease in yield, while areas in green show increase in yield for different years. Yellow regions are regions of no change. The limits for no change were set at -20 to $+20 \mathrm{kWh} / \mathrm{kWp}(\sim 2 \%$ of annual specific yield) and anything higher or lower than these values was recorded as increase or decrease in yields. Increase in yields were observed for most of the regions from 2014 to 2015, while from 2015 to 2016, the yields were either constant or decreased. When looking at differences from 2014 to 2016 compared to 2014-2015, lower yield values were observed in the south of The Netherlands. In general, these differences can also be visualized with scatter plots. The advantage of using mapping techniques to visualize difference data lies not only in knowing how large the change is, but also in being able to see where the change is taking place. Maps of yield differences should be used in conjunction with maps of irradiation differences to explain the yield differences, or one can map the performance ratio differences.
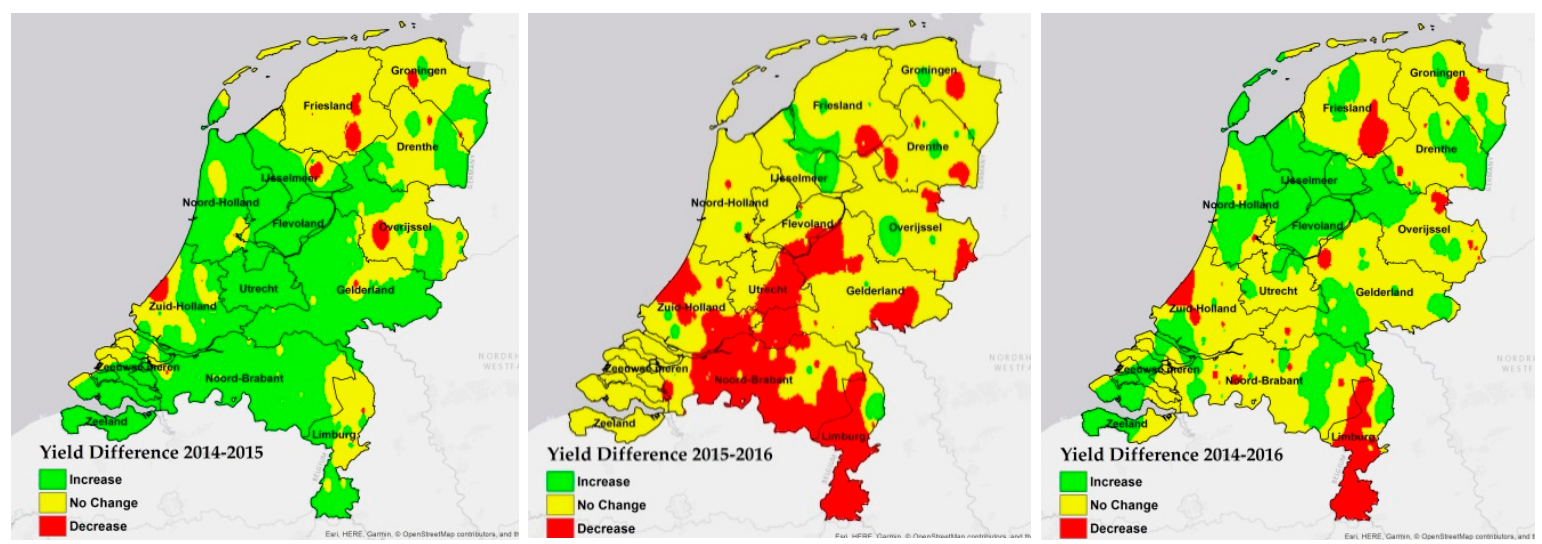

Figure 9. Specific yield difference maps for 2014-2016 for The Netherlands. 


\section{Conclusions}

In this study, GIS has proven to be an excellent tool for visualization of yields and performance of scattered, small-sized, residential PV systems over wide-spread areas. We were able to successfully demonstrate this for The Netherlands and a few other countries like Italy, Germany, and Belgium. Additionally, geo-processing tools (hot-spot analyses, network analyses) could provide useful information to individuals or policy-makers to make informed decisions. This could be done if information (system metadata) pertaining to all the installed PV systems is available.

This paper further provides an update on performance of residential PV systems scattered in a few European countries. It was found that the year 2015 showed a higher specific yield in $\mathrm{kWh} / \mathrm{kWp}$ compared to the years 2014-2016. Performance ratio for The Netherlands did not change with respect to earlier years, although there is an increase in extreme values with the increase in number of installations. Access to high-resolution irradiation data for all the countries is necessary to analyze temporal variations in performance ratios of PV systems. Recent reports suggest an increase in performance ratio values [21-23], however, long-term changes over expected lifetime of the systems should be analyzed to show if performance ratio values still are increasing.

Building up and expanding the present PV performance databases to other countries will provide up-to-date performance maps of more countries. In addition, irradiation maps can be combined with yield maps in order to construct maps of performance to understand the relationship between climatic zones across the world and performance of PV systems.

Author Contributions: Conceptualization and Methodology: B.B.K.; Acquisition of data and initial analysis: P.M.; Analysis and data interpretation: B.B.K.; Writing original draft: P.M. and B.B.K.; Writing Review and Editing: B.B.K. and W.G.J.H.M.v.S.; Funding acquisition: W.G.J.H.M.v.S.

Acknowledgments: This work is part of the International Energy Agency-Photovoltaic Power Systems (IEA-PVPS) Task 13 "Performance and Reliability of Photovoltaic Systems" [24]; we would like to thank all members of this task for their support. This project is partly financially supported by The Netherlands Enterprise Agency (RVO).

Conflicts of Interest: The authors declare no conflict of interest.

\section{References}

1. Santiago, I.; Trillo Montero, D.; Luna Rodríguez, J.; Moreno Garcia, M.; Palacios Garcia, E.J. Graphical Diagnosis of Performances in Photovoltaic Systems: A Case Study in Southern Spain. Energies 2017, $10,1964$. [CrossRef]

2. Mayer, D.; Wald, L.; Poissant, Y.; Pelland, S. Performance Prediction of Grid-Connected Photovoltaic Systems Using Remote Sensing; International Energy Agency: Paris, France, 2008.

3. Nordmann, T.; Clavadetscher, L.; van Sark, W.; Green, M. Analysis of Long-Term Performance of PV Systems; International Energy Agency: Paris, France, 2014.

4. Jahn, U.; Nasse, W. Operational performance of grid-connected PV systems on buildings in Germany. Prog. Photovolt. Res. Appl. 2004, 12, 441-448. [CrossRef]

5. Huld, T.; Suri, M.; Dunlop, E. A GIS-based System for Performance Assessment of Solar Energy Systems over Large Geographical Regions. In Proceeding of Solar 2006 Conference; American Solar Energy Society: Boulder, CO, USA, 2006.

6. Stegner, C.; Dalsass, M.; Luchscheider, P.; Brabec, C.J. Monitoring and assessment of PV generation based on a combination of smart metering and thermographic measurement. Sol. Energy 2018, 163, 16-24. [CrossRef]

7. Drews, A.; de Keizer, A.C.; Beyer, H.G.; Lorenz, E.; Betcke, J.; van Sark, W.G.J.H.M.; Heydenreich, W.; Wiemken, E.; Stettler, S.; Toggweiler, P.; et al. Monitoring and remote failure detection of grid-connected PV systems based on satellite observations. Sol. Energy 2007, 81, 548-564. [CrossRef]

8. Mau, S.; Jahn, U. Performance analysis of grid-connected PV systems. In Proceedings of the European Photovoltaic Solar Energy Conference and Exhibition (EU PVSEC), Dresden, Germany, 4-9 September 2006; pp. 2676-2680.

9. Moraitis, P.; van Sark, W.G.J.H.M. Operational performance of grid-connected PV systems. In Proceedings of the 40th IEEE PVSC, Denver, CO, USA, 8-13 June 2014; pp. 1953-1956. 
10. Moraitis, P.; Kausika, B.B.; van Sark, W.G.J.H.M. Visualization of operational performance of grid-connected PV systems in selected European countries. In Proceedings of the 42nd IEEE PVSC, New Orleans, LA, USA, 14-19 June 2015; pp. 1-3.

11. Solar Log GmbH. Available online: https:/ / www.solar-log.com/en/ (accessed on 15 April 2018).

12. SMA Solar Technology AG-Inverter \& Photovoltaics Solutions. Available online: https://www.sma.de/en/ (accessed on 15 April 2018).

13. Moraitis, P. Review of the Operational Performance of Grid Connected PV Systems. Master's Thesis, Utrecht University, Utrecht, The Netherlands, 2014.

14. Olmo, F.J.; Vida, J.; Foyo, I.; Castro-Diez, Y.; Alados-Arboledas, L. Prediction of global irradiance on inclined surfaces from horizontal global irradiance. Energy 1999, 24, 689-704. [CrossRef]

15. International Electrotechnical Commission. Photovoltaic System Performance Monitoring — Guidelines for Measurement, Data Exchange and Analysis; International Electrotechnical Commission: Geneva, Switzerland, 1998.

16. Tsafarakis, O.; Sinapis, K.; van Sark, W.G.J.H.M. PV System Performance Evaluation by Clustering Production Data to Normal and Non-Normal Operation. Energies 2018, 11, 977. [CrossRef]

17. Burrough, P.A.; McDonnell, R.A.; Lloyd, C.D. Principles of Geographical Information Systems; OUP Oxford: Oxford, UK, 2015; ISBN 978-0-19-874284-5.

18. What Is GIS? I Geographic Information System Mapping Technology. Available online: https://www.esri. com/en-us/what-is-gis/overview (accessed on 15 April 2018).

19. ArcGIS Platform. Available online: http:/ / www.esri.com/software/arcgis (accessed on 13 June 2016).

20. Fouad, M.M.; Shihata, L.A.; Morgan, E.I. An integrated review of factors influencing the perfomance of photovoltaic panels. Renew. Sustain. Energy Rev. 2017, 80, 1499-1511. [CrossRef]

21. Reich, N.H.; Mueller, B.; Armbruster, A.; Sark, W.G.; Kiefer, K.; Reise, C. Performance ratio revisited: Is PR > 90\% realistic? Prog. Photovolt. Res. Appl. 2012, 20, 717-726. [CrossRef]

22. Müller, B.; Hardt, L.; Armbruster, A.; Kiefer, K.; Reise, C. Yield predictions for photovoltaic power plants: Empirical validation, recent advances and remaining uncertainties. Prog. Photovolt. Res. Appl. 2015, 24, 570-583. [CrossRef]

23. Tsafarakis, O.; Moraitis, P.; Kausika, B.B.; van der Velde, H.; Hart't, S.; de Vries, A.; de Rijk, P.; de Jong, M.M.; van Leeuwen, H.-P.; van Sark, W. Three years experience in a Dutch public awareness campaign on photovoltaic system performance. IET Renew. Power Gener. 2017. [CrossRef]

24. IEA-PVPS Task 13-Performance and Reliability of Photovoltaic Systems Website. Available online: http: / / iea-pvps.org/index.php?id=57 (accessed on 28 March 2018). 